\begin{tabular}{cc}
\hline & Jurnal Inovasi Pembelajaran Fisika \\
(INPAFI) & INPAFI \\
\hline
\end{tabular}

\title{
PENGARUH MODEL PEMBELAJARAN KOOPERATIF TIPE GROUP INVESTIGATION TERHADAP HASIL BELAJAR SISWA PADA MATERI GERAK LURUS DI KELAS X SMAN 2 PERCUT SEI TUAN T.A. 2017/2018
}

\author{
Matias Irfan dan Sehat Simatupang \\ Jurusan Fisika FMIPA Universitas Negeri Medan \\ matiasirfan94@gmail.com,simatorop15@gmail.com
}

Diterima: September 2018. Disetujui: Oktober 2018. Dipublikasikan: Nopember 2018

\begin{abstract}
ABSTRAK
Penelitian ini bertujuan untuk mengetahui pengaruh penggunaan model kooperatif tipe group investigation (GI) terhadap hasil belajar siswa pada materi gerak lurus Kelas $\mathrm{X}$ Semester I SMA N 2 Percut Sei Tuan T.A. 2017/2018. Jenis penelitian ini adalah quasi experiment. Populasi penelitian adalah seluruh siswa kelas X yang terdiri dari 4 kelas. Pengambilan sampel dilakukan dengan cara random sampling dengan mengambil 2 kelas secara acak yaitu kelas X IPA-1 dengan menggunakan model pembelajaran kooperatif tipe GI dan kelas X IPA-3 dengan pembelajaran konvensional. Jumlah siswa masing-masing kelas berjumlah 35 orang. Instrumen yang digunakan untuk mengetahui hasil belajar siswa adalah tes hasil belajar dalam bentuk uraian dengan jumlah 8 soal yang sudah dinyatakan valid oleh validator dan lembar observasi aktivitas siswa yang dilakukan oleh dua observer. Uji hipotesis digunakan uji beda (uji t), uji prasyarat yang dilakukan, yaitu uji normalitas dan uji homogenitas maka berdasarkan hasil uji t dapat dikatakan ada pengaruh penggunaan model kooperatif tipe group investigation pada materi gerak lurus Kelas X Semester I SMA N 2 Percut Sei Tuan T.A. 2017/2018.
\end{abstract}

Kata Kunci: model pembelajaran kooperatif tipe group investigation, hasil belajar, gerak lurus

\begin{abstract}
This research is aimed to determine the effect of cooperative learning model group investigation on learning outcomes of students in the subject matter of the straight motion for X class SMA N 2 Percut Sei Tuan T.A. 2017/2018. The study was quasi-experimental. The entire population of tenth grade students of SMA N 2 Percut Sei Tuan consisting of 4 classes. Samples were taken 2 classes are determined by random sampling technique, the class X IPA-1 by using cooperative learning model GI and class XIPA-2 using conventional learning, 35 students in each class. The instrument used in this study were achievement test in the form of essai test form number about 8 question that have been declared valid by the validator and observation sheet student learning activities by two observers. To test the hypothesis used different test (t test), after the prerequisite test is done, the test of normality and homogeneity tests based on hypothesis used t test it can be said there is the influence of cooperative learning model group investigation outcomes of students in the subject matter of the straight motion for X class SMA N 2 Percut Sei Tuan T.A. 2017/2018
\end{abstract}


Matias Irfan dan Sehat Simatupang; Pengaruh Model Pembelajaran Kooperatif Tipe Group Investigation Terhadap Hasil Belajar Siswa Pada Materi Gerak Lurus Di Kelas X

SMA N 2 Percut Sei Tuan T.A. 2017/2018

Keywords: cooperative learning model group investigation, learning outcomes, straight motion.

\section{PENDAHULUAN}

Pendidikan memegang peranan yang sangat penting dalam mempersiapkan sumber daya manusia yang berkualitas. Kualitas sumber daya manusia tidak terlepas dari kualitas tenaga pendidik dalam pendidikan. Tenaga pendidik juga memiliki peranan yang sangat penting yaitu mengemban tanggung jawab dan merencanakan kegiatan belajar dalam upaya menciptakan siswa yang berkualitas. Menurut laporan UNESCO dalam Education For All Global Monitoring Report(EFA-GMR), Indeks Pembangunan Pendidikan Untuk Semua atau The Education for All Development Index (EDI) Indonesia tahun 2014 berada pada peringkat 57 dari 115. Berdasarkan dari hasil tersebut, perlu dilakukan pengembangan pendidikan di Indonesia guna untuk mewujudkan sumber daya manusia (SDM) yang berkualitas agar dapat bersaing secara Internasional. Berbagai upaya senantiasa dilakukan untuk meningkatkan kualitas pendidikan nasional terutama di bidang sains. Sains memiliki beberapa bidang pengetahuan, antara lain, biologi, kimia, fisika, dan ilmu bumi. Salah satu mata pelajaran yang diajarkan di sekolah terkhususnya di SMA adalah Fisika.

Fisika ditempatkan sebagai salah satu mata pelajaran yang penting dan harus dilaksanakan dengan sebaik mungkin agar siswa dapat menguasai konsep dan prinsip Fisika serta mendapatkan hasil belajar yang baik. Pada kenyataannya masih banyak guru menggunakan pembelajaran yang belum sesuai dengan tujuan yang ingin dicapai. Guru lebih berfokus pada mengajar dari pada membelajarkan siswa, sehingga pencapaian tujuan jangka panjang seperti berfikir kritis, kreatif, kerjasama, dan kemampuan pemahaman konsep hampir terabaikan, oleh sebab itu, interaksi yang tercipta di dalam kelas lebih bersifat satu arah. Proses pembelajaran yang bersifat satu arah membuat siswa dapat menguasai materi hanya sebatas apa yang disampaikan oleh guru sehingga berdampak pada hasil belajar siswa.

Menurut hasil observasi yang telah dilakukan di SMA Negeri 2 Percut Sei Tuan pada kelas X MIA yang berjumlah 35 orang dan juga wawancara dengan guru Fisika kelas X MIA, peneliti mendapat informasi bahwa minat siswa terhadap pembelajaran siswa di kelas X MIA SMA Negeri 2 Percut Sei Tuan tergolong rendah. $\mathrm{Hal}$ ini didukung dari hasil wawancara terhadap guru, dimana guru berpendapat bahwa minat siswa terhadap pembelajaran Fisika selalu berubah-ubah, tetapi hal yang sering lebih terjadi mood buruk yang menyebabkan siswa malas belajar. Dari hasil angket siswa didapat bahwa siswa menganggap pelajaran Fisika biasa saja berjumlah $24,37 \%$ siswa, $56,25 \%$ berpendapat cukup membosankan, dan yang berpendapat menyenangkan sebanyak 9,38\%.

Sulitnya pelajaran Fisika dirasakan oleh mayoritas siswa. Beberapa pendapat siswa mengenai pelajaran fisika, antara lain 65,63\% siswa berpendapat bahwa Fisika merupakan pelajaran yang sulit, $34,37 \%$ berpendapat bahwa Fisika merupakan pelajaran yang mudah. Sulitnya pelajaran Fisika tersebut disebabkan beberapa faktor, yaitu $50 \%$ siswa berpendapat karena materi pelajaran yang sulit, 9,37\% siswa berpendapat cara guru menyampai kan materi kurang jelas, $6,25 \%$ orang berpendapat kurang berminat untuk belajar, dan $34,38 \%$ siswa berpendapat situasi kelas yang tidak mendukung. Berdasarkan hasil observasi, situasi kelas yang tidak mendukung dimaksud dengan kurangnya media pelajaran, dan kurangnya buku pelajaran yang dimiliki.

Kegiatan pembelajaran di kelas menurut angket siswa, dimana $78,12 \%$ yang berpendapat bahwa cara guru mengajar di kelas dengan mencatat dan mengerjakan soal, berdiskusi dan tanya jawab dijawab oleh $12,5 \%$ siswa, dan ceramah dijawab oleh 9,38\% siswa

Berdasarkan kenyataan yang telah dipaparkan rendahnya hasil belajar dan kurangnya aktivitas siswa menjadi permasalahan dalam sekolah, sehingga untuk menyikapi masalah di atas, perlu adanya upaya yang dilakukan oleh guru untuk menggunakan model dan metode yang tepat untuk diterapkan dalam proses pembelajaran yang sesuai dengan materi 
yang disampaikan. Model pembelajaran kooperatif tipe Group investigation (GI) merupakan pembelajaran yang dapat melibatkan siswa secara aktif sehingga siswa belajar dengan suasana yang menyenangkan. Model ini biasa digunakan dalam semua subjek pelajaran, pada siswa dalam semua umur, jika guru memang berkeinginan untuk menekankan dalam proses formulasi dan pemecahan masalah dalam beberapa aspek ilmu pengetahuan dibandingkan memasukkan informasi yang belum terstruktur dan belum ditetapkan (Joyce, dkk., 2009:322)

Menurut Sani (2013:131), aktivitas pembelajaran kooperatif menekankan pada kesadaran peserta didik untuk saling membantu mencari dan mengolah informasi, mengaplikasikan pengetahuan dan keterampilan. Tujuan pembelajaran kooperatif adalah melatihkan keterampilan sosial seperti tenggang rasa, bersikap sopan terhadap teman, mengkritik ide orang lain, berani mempertahankan pikiran yang logis dan berbagai keterampilan yang bermanfaat bagi menjalin hubungan intrpersonal. Menurut Aunurrahman (2012:153) dalam kajian mendalam tentang model investigasi kelompok ini, model ini memadukan penelitian akademik, integrasi sosial dan proses belajar sosial.

Peneliti menyimpulkan bahwa dengan menggunakan model pembelajaran kooperatif tipe GI dapat meningkatkan pengetahuan konseptual siswa, didukung berdasarkan uraian mengenai masalah yang telah dibahas, sehingga penulis penting untuk melakukan penelitian dengan menggunakan model pembelajaran kooperatif tipe GI.

Menurut Juwariyah (2013), siswa dilibatkan sejak perencanaan, baik dalam menentukan topik maupun cara untuk mempelajarinya melalui investigasi. Model pembelajaran ini menuntut siswa untuk memiliki kemampuan yang baik dalam berkomunikasi maupun dalam keterampilan proses kelompok.

Hal ini didukung oleh Nasrudin (2014) yang menyimpulkan bahwa kebanyakan siswa lebih suka mengikuti kegiatan pembelajaran dan peningkatan kerjasama siswa dalam pencarian konsep membuat pembelajaran tidak membosankan. Hal senada juga diungkapkan oleh Akçay (2013) yang menyimpulkan bahwa model ini sesuai dalam pembelajaran sains karena membuat siswa untuk belajar dan tertarik dalam penelitian sains.

Sementara menurut Ulfah (2014) berdasarkan hasil penelitian dapat disimpulkan bahwa terdapat perbedaan keterampilan proses sains pada siswa sebelum dan sesudah diajarkan dengan menggunakan model pembelajaran kooperatif tipe group investigation. Hal senada dengan Simanjuntak (2013), berdasarkan hasil penelitian dengan menerapkan model kooperatif tipe group investigation diperoleh perbedaan hasil belajar yang signifikan dibandingkan dengan kelas yang menerapkan model konvensional dan meningkatkan aktivitas siswa dalam pembelajaran.

Adapun yang menjadi tujuan penelitian adalah untuk mengetahui pengaruh model pembelajaran kooperatif tipe group investigation (GI) terhadap hasil belajar siswa pada materi gerak lurus kelas X SMA Negeri 2 Percut Sei Tuan T.A. 2017/2018

\section{METODE PENELITIAN}

Penelitian dilaksanakan di SMA Negeri 2 Percut Sei Tuan yang beralamat di Jl. Pendidikan Pasar XII Desa Bandar Klippa, Kecamatan Percut Sei Tuan Kabupaten Deli Serdang, Sumatera Utara dan waktu pelaksanaan pada semester ganjil Tahun Ajaran 2017/2018 dimulai bulan November sampai Desember 2017. Teknik pengambilan sampel dilakukan dengan cara tehnik sampel kelas acak (random sampling). Sampel kelas diambil dari populasi sebanyak 2 kelas yaitu kelas X IPA-1 dengan menggunakan model kooperatif tipe group investigation (GI) dan kelas X IPA-2 dengan menggunakan pembelajaran konvensional.

Hasil belajar siswa diperoleh dengan memberikan tes pada kedua kelas sebelum diberi perlakuan (pretest). Perlakuan yang dilakukan pada kelas eksperimen menggunakan model pembelajaran kooperatif tipe GI sedangkan di kelas kontrol menggunakan pembelajaran konvensional. Hasil belajar fisika siswa dilakukan dengan memberikan tes pada kedua kelas sesudah diberi perlakuan (posttest). Rancangan 
Matias Irfan dan Sehat Simatupang; Pengaruh Model Pembelajaran Kooperatif Tipe Group Investigation Terhadap Hasil Belajar Siswa Pada Materi Gerak Lurus Di Kelas X

desain penelitian ditunjukkan (Arikunto, 2014) pada Tabel 1.

Tabel 1. Desain control group pretest-posttest

\begin{tabular}{|c|c|c|c|}
\hline Kelas & Pretest & Perlakuan & Posttest \\
\hline Eksperimen & $\mathrm{T}_{1}$ & $\mathrm{X}$ & $\mathrm{T}_{2}$ \\
\hline Kontrol & $\mathrm{T}_{1}$ & $\mathrm{Y}$ & $\mathrm{T}_{2}$ \\
\hline
\end{tabular}

Keterangan:

$\mathrm{T}_{1}=$ Pretest yang dilakukan di kelas eksperimen dan kelas kontrol

$\mathrm{T}_{2}=$ Posttest yang dilakukan di kelas eksperimen dan kelas kontrol

$\mathrm{X}=$ Pembelajaran dengan menggunakan model kooperatif tipe group investigation.

$\mathrm{Y}=$ Pembelajaran dengan menggunakan pembelajaran konvensional.

Alat pengumpul data penelitian adalah tes hasil belajar berbentuk soal uraian dan observasi. Tes hasil belajar digunakan untuk mengetahui kemampuan siswa pada tingkat kognitif dan observasi untuk mengetahui aktivitas belajar siswa.

Uji hipotesis menggunakan uji $t$ yang dikemukakan dilaksanakan dengan membandingkan rata-rata skor hasil belajar yang dicapai baik kelompok eksperimen maupun kelompok kontrol dengan syarat data berdistribusi dan homogen. Data yang diperoleh ditabulasikan kemudian dicari rata-ratanya. Sebelum dilakukan penganalisisan data, terlebih dahulu ditentukan skor masing-masing kelompok sampel lalu dilakukan pengolahan data dengan langkah-langkah sebagai berikut: a) Menghitung nilai rata-rata dan simpangan baku, b) Uji Normalitas, c) Uji Homogenitas dan d) Pengujian Hipotesis (Uji t).

\section{HASIL DAN PEMBAHASAN}

\section{A. HASIL PENELITIAN}

Hasil penelitian yang dilakukan adalah bahwa nilai rata-rata pretest kelas eksperimen sebesar 36,54 dan nilai rata-rata pretest kelas kontrol sebesar 36,26. Nilai pretest kelas eksperimen dan kelas kontrol ditunjukkan pada Tabel 2.
Tabel 2. Data nilai pretest kelas

\begin{tabular}{|c|c|c|}
\hline Nilai & $\begin{array}{c}\text { Kelas } \\
\text { Eksperimen }\end{array}$ & $\begin{array}{c}\text { Kelas } \\
\text { Kontrol }\end{array}$ \\
\hline & $\mathrm{F}$ & $\mathrm{f}$ \\
\hline $18-22$ & 1 & 3 \\
\hline $23-27$ & 3 & 3 \\
\hline $28-32$ & 5 & 4 \\
\hline $33-37$ & 9 & 7 \\
\hline $38-42$ & 9 & 10 \\
\hline $43-47$ & 7 & 6 \\
\hline $48-52$ & 1 & 2 \\
\hline Rata-rata & 36,54 & 36,26 \\
\cline { 2 - 3 } & $\sum=35$ & $\sum=35$ \\
\cline { 2 - 3 }
\end{tabular}

Perlakuan yang berbeda dimana pada kelas eksperimen diberikan pembelajaran dengan model kooperatif tipe GI dan pada kelas kontrol diberikan pembelajaran konvensional, diperoleh bahwa nilai rata-rata posttest kelas eksperimen sebesar 77,2 dan rata-rata posttest kelas kontrol sebesar 66,2. Berdasarkan hasil ini tampak bahwa nilai posttest kelas eksperimen lebih tinggi dibandingkan dengan kelas kontrol. Nilai pretest kelas eksperimen dan kelas kontrol ditunjukkan pada Tabel 3.

Tabel 3. Data nilai posttest kelas eksperimen dan kelas kontrol

\begin{tabular}{|c|c|c|c|c|}
\hline \multirow[t]{2}{*}{ Nilai } & \multicolumn{2}{|c|}{$\begin{array}{c}\text { Kelas } \\
\text { Eksperimen }\end{array}$} & \multicolumn{2}{|c|}{ Kelas Kontrol } \\
\hline & $\begin{array}{c}\text { Frekuens } \\
\text { i }\end{array}$ & $\begin{array}{l}\text { Rata- } \\
\text { Rata }\end{array}$ & $\begin{array}{c}\text { Frekuens } \\
\text { i }\end{array}$ & $\begin{array}{c}\text { Rata } \\
- \\
\text { Rata }\end{array}$ \\
\hline $50-56$ & 1 & \multirow[t]{8}{*}{77,68} & 5 & \multirow{8}{*}{$\begin{array}{c}66,2 \\
1\end{array}$} \\
\hline $57-63$ & 3 & & 9 & \\
\hline $64-70$ & 6 & & 11 & \\
\hline $71-77$ & 7 & & 7 & \\
\hline $78-84$ & 9 & & 2 & \\
\hline $85-91$ & 6 & & 1 & \\
\hline $92-98$ & 3 & & 0 & \\
\hline$\Sigma=$ & 35 & & $\Sigma=35$ & \\
\hline
\end{tabular}

Uji normalitas data pretest dan data posttest kelas eksperimen dengan kelas kontrol menggunakan uji Lilliefors, setelah dilakukan pengujian maka data pretest dan posttest kedua kelas terdistribusi normal. Uji homogenitas pretest dan posttest kelas eksperimen dan kelas 
kontrol menggunakan uji kesamaan dua varians. Berdasarkan hasil pengujian ini data kedua kelompok sampel dinyatakan homogen sehingga layak dilakukan uji hipotesis.

Pretest dilakukan untuk melihat kesamaan kemampuan awal siswa dengan uji dua pihak. Hasil uji hipotesis dua pihak ditunjukkan pada Tabel 4.

Tabel 4. Ringkasan perhitungan uji hipotesis kemampuan pretest

\begin{tabular}{|c|c|c|c|c|}
\hline $\begin{array}{c}\text { Data } \\
\text { Pretest }\end{array}$ & $\begin{array}{c}\text { Rata- } \\
\text { rata }\end{array}$ & t-hitung & $\begin{array}{c}\mathrm{t}- \\
\text { tabel }\end{array}$ & Kesimpulan \\
\hline $\begin{array}{c}\text { Kelas } \\
\text { eksperi- } \\
\text { men }\end{array}$ & 36,54 & 0,147 & 1,997 & $\begin{array}{c}\text { Kemampuan } \\
\text { awal sama }\end{array}$ \\
\cline { 1 - 2 } $\begin{array}{c}\text { Kelas } \\
\text { kontrol }\end{array}$ & 36,26 & & & \\
\hline
\end{tabular}

Posttest dilakukan untuk melihat hasil belajar siswa setelah diberikan perlakuan dengan uji hipotesis satu pihak. Ringkasan uji hipotesis posttest ditunjukkan pada Tabel 5.

Tabel 5. Ringkasan perhitungan Uji hipotesis kemampuan posttest

\begin{tabular}{|c|c|c|c|c|}
\hline $\begin{array}{c}\text { Data } \\
\text { Posttest }\end{array}$ & $\begin{array}{c}\text { Rata- } \\
\text { rata }\end{array}$ & $\begin{array}{c}\mathrm{t}- \\
\text { hitung }\end{array}$ & $\begin{array}{c}\mathrm{t}- \\
\text { tabel }\end{array}$ & Kesimpulan \\
\cline { 1 - 2 } $\begin{array}{c}\text { Eksperi- } \\
\text { men }\end{array}$ & 77,68 & 2,426 & 1,668 & $\begin{array}{c}\text { Ada } \\
\text { perbedaan } \\
\text { yang } \\
\text { signifikan }\end{array}$ \\
\cline { 1 - 2 } Kontrol & 66,21 & &
\end{tabular}

Observasi dilakukan selama kegiatan pembelajaran yang terdiri dari tiga kali pertemuan. Observasi bertujuan untuk mengamati aktivitas belajar siswa di kelas eksperimen dan di kelas kontrol. Hasil observasi para observer seperti Tabel 6.

Berdasarkan Tabel 6 tampak data aktivitas siswa pada kelas eksperimen mengalami peningkatan yaitu pada pertemuan I $60 \%$, pertemuan II $73 \%$, dan pertemuan III $88 \%$. Peningkatan aktivitas siswa tampak pada pertemuan I yang tergolong kurang aktif sampai pertemuan III menjadi kategori aktif. Sedangkan pada kelas kontrol dari pertemuan I 39\%, pertemuan II $42 \%$, dan pertemuan III $47 \%$. Aktivitas siswa dari pertemuan I sampai pertemuan III masih tergolong kurang aktif. Peningkatan aktivitas siswa tidak tampak selama pembelajaran.

Tabel 6. data aktivitas siswa kelas eksperimen dan kelas kontrol

\begin{tabular}{|l|c|c|c|}
\hline \multirow{2}{*}{ KELAS } & \multicolumn{3}{|c|}{ PERTEMUAN } \\
\cline { 2 - 4 } & I & II & III \\
\hline EKSPERIMEN & 59.33 & 72.83 & 87,67 \\
\hline KONTROL & 39.05 & 42.22 & 47.46 \\
\hline
\end{tabular}

\section{B. PEMBAHASAN}

Hasil penelitian menunjukkan bahwa ada pengaruh penggunaan model kooperatif tipe group investigation (GI) terhadap hasil belajar fisika siswa. Berdasarkan hasil penelitian oleh Sulasti (2013) menyimpulkan penerapan model pembelajaran Kooperatif Tipe Group Investigation (GI) dapat meningkatkan aktivitas belajar siswa yang dilihat dari peningkatan hasil belajar siswa dari siklus I ke siklus II. Sedangkan menurut Sholikha (2014), dilihat dari rerata sel diperoleh bahwa pada penerapan model pembelajaran kooperatif tipe GI, prestasi belajar antara siswa pada saat sesudah diterapkan model kooperatif tipe GI lebih baik daripada sebelum diterapkan model kooperatif tipe GI.

Model pembelajaran kooperatif tipe GI memberikan pengaruh terhadap hasil belajar siswa tidak terlepas dari fase-fase model pembelajaran kooperatif tipe GI yang berjalan selama proses pembelajaran. Hal tersebut senada dengan Wiratana (2013), berdasarkan peneliannya menyimpulkan bahwa pembelajaran kooperatif tipe GI dengan sintaksnya sangat memungkinkan untuk mengembangkan keterampilan proses siswa dan meningkatkan hasil belajar siswa. Sejalan dengan penelitian oleh Wijayanti (2014), dari penelitiannya didapat bahwa pada aspek persiapan alat dan bahan dan aspek ketrampilan memakai alat pada kelas eksperimen mempunyai rata-rata skor dengan kategori sangat tinggi sedangkan pada kelas kontrol mempunyai ratarata skor dengan kategori tinggi. Hal ini di karenakan dalam pembelajaran group investigation yang diterapkan pada kelas 
Matias Irfan dan Sehat Simatupang; Pengaruh Model Pembelajaran Kooperatif Tipe Group Investigation Terhadap Hasil Belajar Siswa Pada Materi Gerak Lurus Di Kelas X

eksperimen mengharuskan siswa untuk merencanakan proses penemuan konsep sendiri dari permasalahan yang diberikan. Hal tersebut menjadikan siswa pada kelas eksperimen lebih mandiri dan terampil dalam mempersiapkan dan memakai bahan dan alat untuk praktikum

Pelaksanaan model kooperatif tipe GI, terdapat enam tahap yang dilakukan peneliti. Tahap pertama yaitu mengidentifikasi topik dan mengatur ke dalam kelompok-kelompok penelitian, peneliti mengajukan subtopik untuk dipelajari berkaitan dengan pelajaranteori kinetik gas untuk dikerjakan oleh siswa secara kelompok, dan siswa dapat berdiskusi tentang subtopik yang diberikan. Siswa berusaha untuk menunjukkan sikap rasa ingin tahu dan juga berpikir dengan mandiri sesuai dengan kemampuan masing-masing. Tahap ini siswa diajak untuk saling bertukar gagasan dan pendapat dengan teman sekelompoknya, sehingga pada tahap ini siswa terlihat tertarik dan termotivasi untuk masuk pada tahap berikutnya.

Tahap kedua yaitu merencanakan investigasi di dalam kelompok. Siswa duduk berkelompok dengan teman satu kelompok yang telah ditentukan dan menyamakan pemikiran mengenai apa yang telah dibahas pada tahap sebelumnya. Setiap siswa dalam kelompok saling berinteraksi dan berdiskusi memformulasikan sebuah masalah yang dapat diteliti, memutuskan bagaimana pelaksanaannya, dan menentukan sumber - sumber yang dibutuhkan untuk melakukan investigasi. Interaksi selama tahap ini menghasilkan kesepakatan bersama dalam kelompoknya. Pada tahap ini kerjasama antarsiswa mulai terlihat dan suasana belajar lebih menyenangkan karena siswa dapat saling bertukar pendapat dengan teman satu kelompoknya.

Tahap ketiga yaitu melaksanakan investigasi, peneliti membagikan Lembar Kerja Peserta Didik (LKPD) kepada masing-masing kelompok. Peneliti juga menyediakan alat dan bahan yang akan digunakan siswa untuk melakukan percobaan. Siswa terlihat lebih aktif dan mulai memiliki rasa ingin tahu tentang apa yang akan dilakukan selanjutnya. Kerjasama dalam kelompok mulai terlihat ketika siswa mulai saling bertanya kepada teman-teman satu kelompoknya tentang alat dan bahan yang telah disediakan peneliti. Rasa ingin tahu siswa mulai muncul ketika mereka mengamati alat dan bahan yang diberikan dan mulai ingin menggunakan alat dan bahan tersebut. Peneliti membimbing siswa dalam melakukan percobaan. Peneliti terlebih dahulu menjelaskan bagaimana cara menggunakan alat dan bahan yang telah disedikan. Peneliti mengajak siswa untuk melakukan percobaan sesuai dengan LKPD yang telah diberikan peneliti. Siswa melakukan percobaan dengan teliti dan hati-hati dalam menggunakan alat dan bahan, siswa saling bekerja sama dengan anggota kelompok masingmasing sesuai dengan langkah-langkah yang ada di LKPD, siswa terlihat aktif dan kompak. Siswa mulai mengetahui jawaban mengenai permasalahan yang diajukan peneliti sebelumnya dan yang ada di LKPD, setiap kelompok berusaha menyelesaikan persoalan yang diberikan dan menuliskan hasilnya di LKPD. Peneliti mengamati masing - masing siswa dalam kelompok bersama dengan dua orang observer untuk mengetahui perkembagan aktivitas siswa pada setiap pertemuan.

Tahap keempat yaitu menyiapkan laporan akhir. Siswa melakukan pengumpulan data, mengintegrasikan semua bagian menjadi satu keseluruhan, dan merencanakan sebuah presentasi yang dapat menyajikan semua hasil investigasi dan dapat menarik perhatian kelompok lain. Peneliti memastikan gagasangagasan presentasi yang akan dilakukan cukup realistis dan menarik, dan memastikan semua orang di dalam kelompok memainkan sebuah peranan penting dalam presentasi.

Tahap kelima yaitu mempresentasikan laporan akhir, peneliti meminta satu kelompok untuk maju ke depan kelas dan berbagi hasil investigasi/penyelidikan yang dilakukan dengan anggota kelompok yang lain. Kelompok lain dapat membandingkan hasil investigasi yang diperoleh sehingga akan timbul tanya jawab pada tahap ini antara kelompok yang presentasi dengan kelompok lain yang mendengarkan. Pemahaman siswa dapat meningkat terhadap materi yang sedang dipelajari.

Tahap keenam yaitu evaluasi pencapaian. Siswa bisa menanyakan bagian 
mana yang kurang dipahami baik pada kelompok yang presentasi ataupun kepada peneliti. Evaluasi dilakukan untuk mengoreksi kesalahan konsep yang timbul atau meluruskan pemahaman siswa yang keliru tentang teori kinetik gas, sehingga siswa memahami konsep teori kinetik gas yang sebenarnya

\section{KESIMPULAN DAN SARAN}

\section{A. KESIMPULAN}

Berdasarkan analisis data hasil penelitian yang dilakukan dapat disimpulkan bahwa:

Hasil penelitian ini menunjukkan bahwa nilai posttest kelas eksperimen lebih tinggi dibandingkan dengan kelas kontrol dengan perbedaan peningkatan sebesar $17,37 \%$ lebih tinggi dari peningkatan hasil belajar kelas control sehingga dapat dikatakan bahwa model pembelajaran kooperatif tipe group investigation memberikan pengaruh yang signifikan terhadap hasil belajar siswa pada materi gerak lurus.

\section{B. SARAN}

Pelaksanaan model pembelajaran ini masih banyak kelemahan dan kendala yang dihadapi peneliti sehingga keterlaksanaan model ini tidak sepenuhnya tercapai. Berdasarkan pembahasan hasil penelitian maka sebagai tindak lanjut dari penelitian ini disarankan kepada peneliti selanjutnya diharapkan lebih mampu memfokuskan siswa pada saat melakukan percobaan/praktikum dengan lebih tegas mengarahkan siswa terutama dalam prosedur percobaan berlangsung, dan juga diharapkan untuk peneliti selanjutnya diharapkan membuat jumlah siswa dalam setiap kelompok cukup 3-4 orang agar semua siswa dapat bekerja dan berperan aktif dalam setiap kelompok, siswa sebaiknya dikelompokkan dengan yang jaraknya dekat, sehingga tidak memakan banyak waktu dalam menyusun meja dan kursi.

\section{DAFTAR PUSTAKA}

Akçay, N. O., dan Doymuş, K., (2013), The Effects of Group investigation and Cooperative Learning Techniques Applied in Teaching Force and Motion Subjects on Students' Academic
Achievements, Journal of Educational

Sciences Reserch, 2 (3), 116-120

Aunurrahman, (2012), Belajar dan Pembelajaran, Bandung: Alfabeta

Joyce, B., Weil, M., dan Calhoun, E., (2011), Model of Teaching (Model-model Pengajaran), Diterjemahkan oleh Achmad Fawaid dan Ateilla Mirza, Yogyakarta : Pustaka Pelajar

Juwariah, S., (2013), Penggunaan Metode Group investigation Untuk Meningkatkan Keaktifan Belajar Dan Hasil Belajar Siswa Pada Mata Pelajaran Matematika Di Kelas X A SMA Arofah 2 Klego Tahun Ajaran 2012 / 2013, Jurnal Ilmiah, 2 (3), 5-12

Nasrudin, J. H, (2014), Improvement Thingking Skills And Scientific Attitude Using The Implementation Of "GroupInvestigation Cooperative Learning" Contextual Oriented At Acid, Base And Salt Topic In Junior High School, Jurnal Ilmiah, 5 (3), 8-14

Sani, R. A. (2013), Inovasi Pembelajaran, Jakarta : Bumi Aksara

Sholikhah, O. H., Budiyono, dan Saputro, D. R. S., Eksperimentasi Model Pembelajaran Kooperatif Tipe Group Investigation (Gi) Dan Numbered Heads Together (Nht) Pada Materi Garis Singgung Lingkaran Ditinjau Dari Kecerdasan Majemuk Siswa Kelas VIII SMP Negeri Se-Kota Madiun Tahun Ajaran 2013/2014, Jurnal Elektronik Pembelajaran Matematika, 2 (7), 727-729

Simanjuntak, S. L. dan Siregar, N., (2014), Pengaruh Model Pembelejaran Kooperatif Tipe Group Investigation Terhadap Hasil Belajar Pada Materi Listrik Dinamis, Jurnal Inpafi 2 (2), 172177

Sulasti, N. W., Lasmawan, I. W., dan Landrawan, I. W., (2013), Penerapan Model Pembelajaran Kooperatif Tipe Group Investigation (GI) Untuk Meningkatkan Aktivitas dan Hasil Belajar Siswa Dalam Pelajaran PKn Di 
Matias Irfan dan Sehat Simatupang; Pengaruh Model Pembelajaran Kooperatif Tipe Group Investigation Terhadap Hasil Belajar Siswa Pada Materi Gerak Lurus Di Kelas X

Kelas XI IPA 1 SMA Negeri 1 Sawan

Tahun Ajaran 2012/2013, Artikel, 2-12

Ulfah, A., (2014), Pengaruh Model Pembelajaran

Group investigation Terhadap

Keterampilan Proses Sains Pada Materi

Koloid Di SMA, Jurnal Inpafi, 2 (2),

172-177

Wijayanti, A. D., dan Susatyo, E. B., (2014),

Penerapan Pembelajaran Group

Investigation Berbasis Inkuiri

Terbimbing Untuk Meningkatkan

Hasil Belajar Koloid, Jurnal Inovasi

Pendidikan Kimia, 8 (1), 1300-1308

Wiratana, I. K., Sadia, I. W., dan Suma, K., Pengaruh Model Pembelajaran Kooperatif Tipe Investigasi Kelompok (Group Investigation) Terhadap Keterampilan Proses Dan Hasil Belajar Sains Siswa Smp, e-Journal Program Pascasarjana Universitas Pendidikan Ganesha, 3 (2), 7-12 